\title{
Transcutaneous Peptide Immunotherapy of Japanese Cedar Pollinosis Using Solid-in-Oil Nanodispersion Technology
}

\author{
Momoko Kitaoka, ${ }^{1}$ Yoko Shin, ${ }^{1}$ Noriho Kamiya, ${ }^{1,2}$ Yoshinori Kawabe, ${ }^{3}$ \\ Masamichi Kamihira, ${ }^{3}$ and Masahiro Goto ${ }^{1,2,4}$
}

Received 17 March 2015; accepted 8 May 2015; published online 19 May 2015

\begin{abstract}
Peptide immunotherapy is an attractive approach to relieve allergic symptoms such as rhinitis and asthma. Treatment of Japanse cedar pollinosis (Cryptomeria japonica; $\mathrm{Cj}$ ), from which over one quarter of Japanese population suffer, is becoming a great concern. Recently, oral feeding of a peptide (7crp) consisting of seven immunodominant human T cell epitopes derived from two enzymes present in $\mathrm{Cj}$ pollen was demonstrated to have a benefit in treating $\mathrm{Cj}$ pollinosis. In this work, we aimed to apply a novel transcutaneous administration system as a simple and easy peptide delivery for an immunotherapy using a $\mathrm{T}$ cell epitope peptide. A modified $7 \mathrm{crp}$ peptide $(7 \mathrm{crpR})$ which contained triarginine linkers between each epitopes was designed to increase water solubility and was encapsulated in a unique solid-in-oil (S/O) nanodispersion. The S/O nanodispersion consists of a nano-sized peptide-surfactant complex dispersed in an oil vehicle. The S/O nanopartilces having an average diameter of $230 \mathrm{~nm}$ facilitated the permeation of the peptide $7 \mathrm{crpR}$ into the skin and suppressed serum total $\operatorname{IgE}$ and antigen-specific IgE levels in a $\mathrm{Cj}$ pollinosis mouse model. Transcutaneous administration of the $\mathrm{T}$ cell epitope peptide using the S/O nanodispersion system has potential for future simple and easy immunotherapy of $\mathrm{Cj}$ pollinosis.
\end{abstract}

KEY WORDS: epitope peptide; immunotherapy; pollinosis; solid-in-oil nanodispersion; transdermal drug delivery.

\section{INTRODUCTION}

Allergic symptoms caused by environmental aeroallergens, such as house dust mites, spores, and pollens, are social problems in industrialized countries. Above all, seasonal allergic rhinitis caused by Japanese cedar (Cryptomeria japonica; $\mathrm{Cj}$ ) pollen is a significant concern in Japan (1). The prevalence of $\mathrm{Cj}$ pollinosis is increasingly affecting over one quarter of the Japanese population (2). Pharmacotherapy is the main approach to treat $\mathrm{Cj}$ pollinosis and reduces allergic symptoms; however, symptomatic treatment does not cure allergy. Since Cj pollinosis is a type I allergy mediated by immunoglobulin (Ig) E, antigenspecific immunotherapy is anticipated to be curative. Although conventional immunotherapy using antigen molecules has a risk

Electronic supplementary material The online version of this article (doi:10.1208/s12249-015-0333-x) contains supplementary material, which is available to authorized users.

${ }^{1}$ Department of Applied Chemistry, Graduate School of Engineering, Kyushu University, 744 Moto-oka, Fukuoka, 819-0395, Japan.

${ }^{2}$ Center for Future Chemistry, Kyushu University, 744 Moto-oka, Fukuoka, 819-0395, Japan.

${ }^{3}$ Department of Chemical Engineering, Graduate School of Engineering, Kyushu University, 744 Moto-oka, Fukuoka, 819-0395, Japan.

${ }^{4}$ To whom correspondence should be addressed. (e-mail: m-goto@mail.cstm.kyushu-u.ac.jp) of acute anaphylaxis, especially when administered by injection, sublingual immunotherapy has been demonstrated to be a safer approach $(3,4)$, with long-lasting effects after discontinuation $(5,6)$, and is supported by health insurance in Japan. However, risks of adverse side effects remain when whole allergen molecules are used for immunotherapy.

Recently, the use of short, antigen-derived peptides was shown to be an effective immunotherapy (7). The peptides contain only T cell epitope domains from antigen molecules, thus lack the ability to cross-link IgE molecules which subsequently bind to IgE receptors on the surface of mast cells or basophils. Consequently, the T cell epitope peptide leads to suppression of IgEmediated allergic reactions including anaphylaxis. Immunotherapy using $T$ cell epitope peptides was successfully demonstrated to induce immune tolerance in allergy models of house dust mites and Birch pollens $(8,9)$. For the Cj pollinosis, two enzymes (Cry j 1 and Cry j 2) present in $\mathrm{Cj}$ pollen are considered the major allergens (10), and several immunodominant human T cell epitopes were determined and evaluated using blood samples from Cj pollinosis patients (11-13). Peptides comprised of multiple T cell epitopes administered orally effectively reduced allergic responses represented by allergen-specific antibody responses, $\mathrm{T}$ cell proliferation, and number of sneezing events (14-17). Oral administration of protein/peptide drugs including edible vaccines is needle free and convenient and utilizes the whole length of the gastrointestinal tract; however, dosage and vaccine-food interactions are the concerns (18). 
Nanoparticle- and microparticle-based drug delivery systems are recognized as beneficial techniques because of their stability, increased bioavailability, and modulated drug release (19). Previously, our group proposed an original transcutaneous vaccine delivery technique based on a solid-in-oil $(\mathrm{S} / \mathrm{O})$ nanodispersion system. Using an antigen model protein, ovalbumin (OVA), the S/O nanodispersion system efficiently induced antigen-specific antibodies in murine models using a simple patch $(20,21)$. The $\mathrm{S} / \mathrm{O}$ nanodispersion is an oil-based dispersion of nano-sized particles containing protein/peptide molecules coated with surfactant molecules, which is formed by lyophilization of a water-in-oil emulsion and re-dispersion in an oil-vehicle. Hydrophilic biomolecules such as proteins and peptides can penetrate the hydrophobic stratum corneum (SC), the outermost layer of the skin, assisted by surfactants and oil-vehicle. Transcutaneous drug administration has advantages compared with conventional needle-based administration: reduced pain, avoidance of first pass metabolism, and effective immunization by utilizing the skin immune system. In addition, there are no risks of needle-related injuries or transmission of pathogens.

Here, we first report a transcutaneous administration of $\mathrm{T}$ cell epitope peptide for immunotherapy using the $\mathrm{S} / \mathrm{O}$ nanodispersion system. For therapeutic treatment, we used a recombinant peptide comprising seven human $\mathrm{T}$ cell epitopes derived from Cry $\mathrm{j} 1$ and 2 with modification to enhance water solubility (11). An integrated peptide of seven $\mathrm{T}$ cell epitopes containing triarginine spacers between the epitopes (7crpR) was produced in Escherichia coli and coated with surfactants. Size and skin permeation efficiency of the $\mathrm{S} / \mathrm{O}$ nanodispersion containing $7 \mathrm{crpR}$ was characterized; then, the serum total and antigen-specific $\mathrm{IgE}$ levels in a mouse model of $\mathrm{Cj}$ pollinosis were evaluated after transcutaneous administration.

\section{MATERIALS AND METHODS}

\section{Animals}

Female B10.S mice (7 weeks old) were purchased from Japan SLC (Shizuoka, Japan) and housed in a temperaturecontrolled room $\left(23^{\circ} \mathrm{C}\right)$ with a 12 -h light/dark cycle. Animal experiments were performed with approval of the Ethics Committee for Animal Experiments (A26-267-0, Kyushu University) and in accordance with the Guide for the Care and Use of Laboratory Animals (Science Council of Japan).

\section{Materials}

Cyclohexane, dithiothreitol, ethanol (99\%), acetonitrile, and imidazole were purchased from Wako Pure Chemical Industries (Kyoto, Japan). Isopropyl myristate (IPM) was obtained from Tokyo Kasei Kogyo (Tokyo, Japan). A surfactant sucrose laurate (L-195) was kindly provided by Mitsubishi-Kagaku Foods (Tokyo, Japan). Cj pollen extract (Cedar Pollen Extract-Cj) was purchased from Cosmo Bio (Tokyo, Japan). Imject Alum was sourced from Thermo Fisher scientific (Waltham, MA, USA). Histamine was from Nacalai Tesque (Kyoto, Japan).

\section{Methods}

\section{Preparation of the T Cell Epitope Peptide 7crpR}

The peptide $7 \mathrm{crpR}$ design was based on a previously reported artificial peptide (7crp) containing human T cell epitope determinants from Cry j 1 (212-224, 235-247, 312-330) and Cry j 2 (74-89, 96-107, 192-204, 356-367) (11,17). 7crpR additionally contained triarginine linkers between determinants and hexahistidine-tag at the C-terminus (Fig. 1). A doublestranded DNA encoding the peptide $7 \mathrm{crpR}$ with an optimized codon for $E$. coli expression was custom-synthesized at Medical and Biological Laboratories (Nagoya, Japan). The 7crpR gene was cloned into the pET22b(+) plasmid vector, which was transformed into $E$. coli strain BL21(DE3). The peptide $7 \mathrm{crpR}$ was produced by $E$. coli, purified, and stored at $4{ }^{\circ} \mathrm{C}$ until use (see Electronic supplementary material for the production condition of $7 \mathrm{crpR})$.

\section{Preparation of S/O Nanodispersions Containing 7crpR}

A S/O nanodispersion was prepared as previously reported (20). A $2.0-\mathrm{mL} 7 \mathrm{crpR}$ aqueous solution $(0.5 \mathrm{mg} / \mathrm{mL})$ and a 4.0-mL L-195 cyclohexane solution $(12.5 \mathrm{mg} / \mathrm{mL})$ were homogenized with a polytron homogenizer (Kinematica AG, Luzern, Switzerland) at 26,000 rpm for $2 \mathrm{~min}$ to obtain a water-in-oil (W/O) emulsion. The W/O emulsion was incubated in liquid nitrogen for $20 \mathrm{~min}$, and then lyophilized for $24 \mathrm{~h}$ with a freeze-dryer (Eyela, Tokyo, Japan). The resultant viscous surfactant-protein complex was dispersed in IPM to prepare a $\mathrm{S} / \mathrm{O}$ nanodispersion.

\section{Particle Size}

The mean diameter and polydispersity index for the S/O nanodispersion was measured by dynamic light scattering (DLS) using Zatasizer NanoZS (Malvern, Worcestershire, UK).

\section{Scanning Electron Microscopy}

Morphological appearance of the surfactant-peptide complex was observed by scanning electron microscopy (SEM) using Inspect S50 (FEI, Hillsboro, OR, USA). The complex was dispersed in cyclohexane (7crpR concentration $0.1 \mathrm{mg}$ / $\mathrm{mL})$. A droplet $(5 \mu \mathrm{L})$ was placed onto a carbon conductive double-sided adhesive tape and dried overnight. After being sputter-coated with gold/palladium alloy, the sample was analyzed at an acceleration voltage of $5 \mathrm{kV}$.

\section{In Vitro Skin Permeation Test}

The peptide was labeled with Cy3 using a kit (Cy3 MonoReactive Dye Pack, GE Healthcare) according to the manufacturer's instructions. In vitro peptide permeation test was performed as previously described (21), using customfabricated Franz diffusion cells (effective diffusion area, $0.785 \mathrm{~cm}^{2}$; receptor volume, $5 \mathrm{~mL}$ ). Yucatan micropig (YMP) back skin was cut into $3-\mathrm{cm}^{2}$ pieces and was set on a Franz diffusion cell. The S/O nanodispersion containing Cy3-7crpR $(1 \mathrm{mg} / \mathrm{mL}, 200 \mu \mathrm{L})$ was applied onto the skin for 24 or $48 \mathrm{~h}$ at 


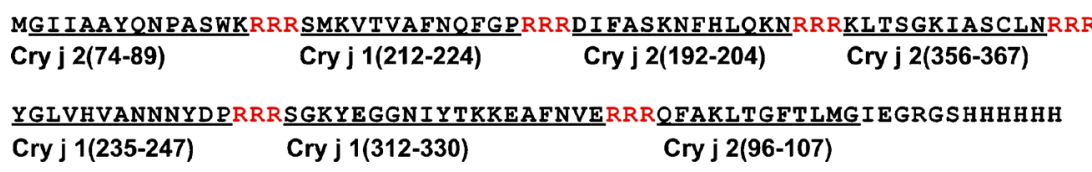

Fig. 1. Amino acid sequences of $7 \mathrm{crpR}$. Underlined sequences represent the $\mathrm{T}$ cell epitope domains derived from the enzymes Cry j 1 and Cry j 2. Numbers in parenthesis denote amino acid positions in the enzymes $32.5^{\circ} \mathrm{C}$. Cy3-7crpR in PBS $(1 \mathrm{mg} / \mathrm{mL}, 200 \mu \mathrm{L})$ was also put on the YMP skin under the same conditions as a control. Before the extraction of the peptide, the skin was washed with an extraction solution, a mixture of water, ethanol, and acetonitrile $(2: 1: 1, v / v / v)$. Then, the skin was cut into pieces and the peptide was extracted with the $0.5 \mathrm{~mL}$ of extraction solution for $12 \mathrm{~h}$ under dark. The cumulative amounts of Cy3-7crpR were calculated from the fluorescence intensities measured with a fluorescence spectrometer LS55 (PerkinElmer, Waltham, Ma, USA) at Ex/Em=540 nm/570 nm.

\section{Histological Observation of the Mouse Ear Skin}

Tissue papers impregnated with the $\mathrm{S} / \mathrm{O}$ nanoparticle containing Cy3-7crpR (1 mg/mL, $525 \mu \mathrm{L}$ each) was patched onto mouse ears for $24 \mathrm{~h}$. After removal of patches, ear tissues were washed with $99 \%$ ethanol, followed by a Milli-Q wash. Tissues were immersed in $4 \%$ paraformaldehyde for $6 \mathrm{~h}$ then frozen in Tissue-tek O.C.T. compound (Sakura Finetek, Tokyo, Japan). Tissue sections (16 $\mu$ m thick) were prepared with a cryostat microtome (Leuca, Wetzlar, Germany). Fluorescence images were observed using a fluorescence microscope BZ-9000 with a $\times 20$ objective lens (Keyence, Osaka, Japan).

\section{Sensitization and Peptide Administration Procedures}

Mice ( 9 weeks old) were sensitized as previously described $(16,22)$. Briefly, a mixture of $10 \mu \mathrm{g}$ of $\mathrm{Cj}$ pollen extract and $4 \mathrm{mg}$ of Imject Alum was subcutaneously injected to mice three times with 1 -week intervals. Six days after the final sensitization, $5 \mu \mathrm{L}$ of histamine dihydrochloride in PBS $(2 \mu \mathrm{g} / \mathrm{mL})$ was dropped into each nostril. Subsequently, $5 \mu \mathrm{L}$ of $\mathrm{Cj}$ pollen extract diluted with PBS $(400 \mu \mathrm{g} / \mathrm{mL})$ was dropped into each nostril for five consecutive days from the day after histamine administration.

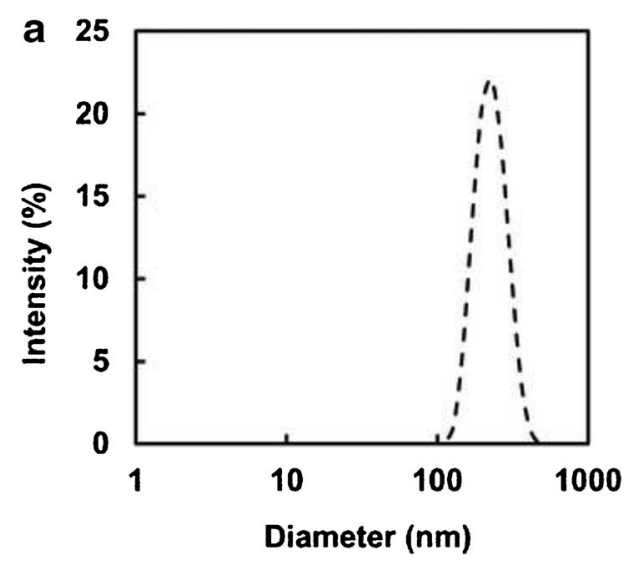

For therapeutic treatment, tissue papers impregnated with $\mathrm{S} / \mathrm{O}$ nanodispersion containing $7 \mathrm{crpR}$ were patched onto both auricles $(0.2$ or $1 \mathrm{mg} / \mathrm{mL}, 25 \mu \mathrm{L}$ each $)$ at 6 weeks after intranasal antigen challenge. S/O nanodispersions were administered once a week for three consecutive weeks. The peptide $7 \mathrm{crpR}$ PBS solution was also administered with patches $(1 \mathrm{mg} / \mathrm{mL}, 25 \mu \mathrm{L}$ each $)$ or by subcutaneous injection $(1 \mathrm{mg} / \mathrm{mL}, 50 \mu \mathrm{L})$ as a negative or a positive control. Two weeks after the last peptide administration, $5 \mu \mathrm{L}$ of $\mathrm{Cj}$ pollen extract in PBS $(400 \mu \mathrm{g} / \mathrm{mL})$ was challenged into both nostrils for five consecutive days. Blood was collected for serum 3 days after final antigen challenge.

\section{Measurement of Total IgE and Cry j 1-Specific IgE}

Total serum IgE was measured using an enzyme-linked immunosorbent assay (ELISA) kit (Mouse IgE ELISA Ready-SET-Go; eBioscience, San Diego, CA, USA). Briefly, plates were coated with anti-mouse $\operatorname{IgE}$ at $4^{\circ} \mathrm{C}$ overnight, washed, and blocked. Then, diluted serum (1:500) was added and detected with biotin-labeled anti-mouse IgE. After coloring reaction with tetramethylbenzidine at room temperature for $15 \mathrm{~min}$ in the dark, the reaction was stopped by adding $1 \mathrm{M}$ sulfuric acid. Optical density at $450 \mathrm{~nm}$ was measured by microplate reader (BioTek Instruments, Winooski, VT, USA). Serum Cry j 1-specific IgE was measured according to the previous report (23). Briefly, plates were coated with anti-mouse IgE, washed, and blocked. Diluted serum (1:30) was added to the plates, and Cry j 1-specific IgE was detected with $100 \mu \mathrm{L}(2.5 \mu \mathrm{g} / \mathrm{mL})$ of biotin-labeled Cry j 1 (Hayashibara, Okayama, Japan). Serum standards were obtained from mice to which $\mathrm{Cj}$ pollen extract was administered by intraperitoneal injection eight times with 1 -week intervals, and arbitrarily assigned to a value of 10,000 relative units $(\mathrm{RU}) / \mathrm{mL}$ of Cry j 1-specific IgE. Samples were assayed in

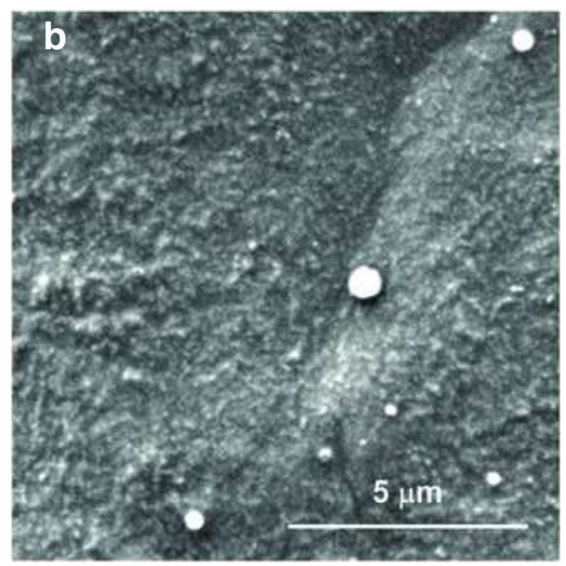

Fig. 2. Size distribution of $S / O$ nanodispersion containint $7 \operatorname{crpR}$ (a) and $S E M$ images of $S / O$ nanoparticles at a magnification of $\times 10,000$ (b) 
triplicate, and results were expressed as the mean \pm standard deviation (SD) $(n=4-6)$. Statistical analysis was performed using one-way analysis of variance (ANOVA) followed by Tukey's multiple comparison test $(* p<0.05$, ** $p<0.01$, *** $p<0.0001)$.

\section{RESULTS}

\section{Preparation of S/O Particles Containing a $\mathbf{T}$ cell Epitope Peptide}

The recombinant peptide $7 \mathrm{crpR}$ expressed using an E. coli system was analyzed by sodium dodecyl sulfatepolyacrylamide gel electrophoresis (SDS-PAGE), and the result showed a single band at around $15 \mathrm{kDa}$ after purification (Supplementary Fig. S1). The S/O nanodispersion containing $7 \mathrm{crpR}$ was prepared following to our standard protocol $(20,22)$, and was subjected to DLS analysis. As a result, the nanoparticle had a mean diameter of $230 \mathrm{~nm}$ with a polydispersity index of $0.250-0.281$ in IPM (Fig. 2a). SEM images of the surfactant-peptide complex showed particles of a round shape, smaller than $500 \mathrm{~nm}$ (Fig. 2b, c). The physical appearance of the S/O nanodispersions was slightly translucent, although the peptide itself was insoluble in IPM and formed a precipitation (Supplementary Fig. S2).

\section{In Vitro and In Vivo Skin Permeation Efficiencies of 7crpR-Containing S/O Nanodispersion}

In vitro and in vivo skin penetration efficiencies of the peptide were examined using a fluorescence Cy3-labeled 7crpR. Employing a Cy3-dye labeling kit, approximately $30 \%$ of $7 \mathrm{crpR}$ was labeled with $\mathrm{Cy} 3$ by a calculation based on UV absorbance. Figure 3 a shows cumulative amounts of Cy3-7crpR in the YMP skins treated with a peptide PBS solution and a $\mathrm{S} / \mathrm{O}$ nanodispersion. The $\mathrm{S} / \mathrm{O}$ nanodispersion system facilitated permeation of the peptide 4.8 -fold compared to the PBS solution in $48 \mathrm{~h}$. Mouse auricle sections processed with 7crpR PBS solution for $24 \mathrm{~h}$ had weak fluorescence in the SC layer; however, auricle sections treated with the S/O nanodispersion exhibited strong fluorescence at $\mathrm{SC}$ layer with a weak signal in epidermis (Fig. 3b). No fluorescence image was observed in the mouse auricle sections treated with PBS without peptide. Thickening of SC layer was observed by applying the S/O nanodispersion patch for another 24 h (Supplementary Fig. S3).

\section{Therapeutic Treatment of Pollinosis Mouse Models}

We developed a B10.S mouse model of allergic rhinitis responding to $\mathrm{Cj}$ pollen antigen following the previous description (Fig. 4a) (16). Sensitization was confirmed by induction of serum total IgE which was not detected in the serum of an unprimed mouse. The mouse model was reported to be suitable as a mouse model developing Japanese cedar pollinosis with nasal symptoms (24), and its symptoms to be reduced by inoculation of peptide $7 \mathrm{crp}(16,17)$. We examined the therapeutic effect of transcutaneous administration of $7 \mathrm{crpR}$ to a rhinitis mouse model. A PBS solution of $7 \mathrm{crpR}(50 \mu \mathrm{g})$ was transcutaneously administered three times as a control. Total serum IgE levels from mice three times transcutaneously
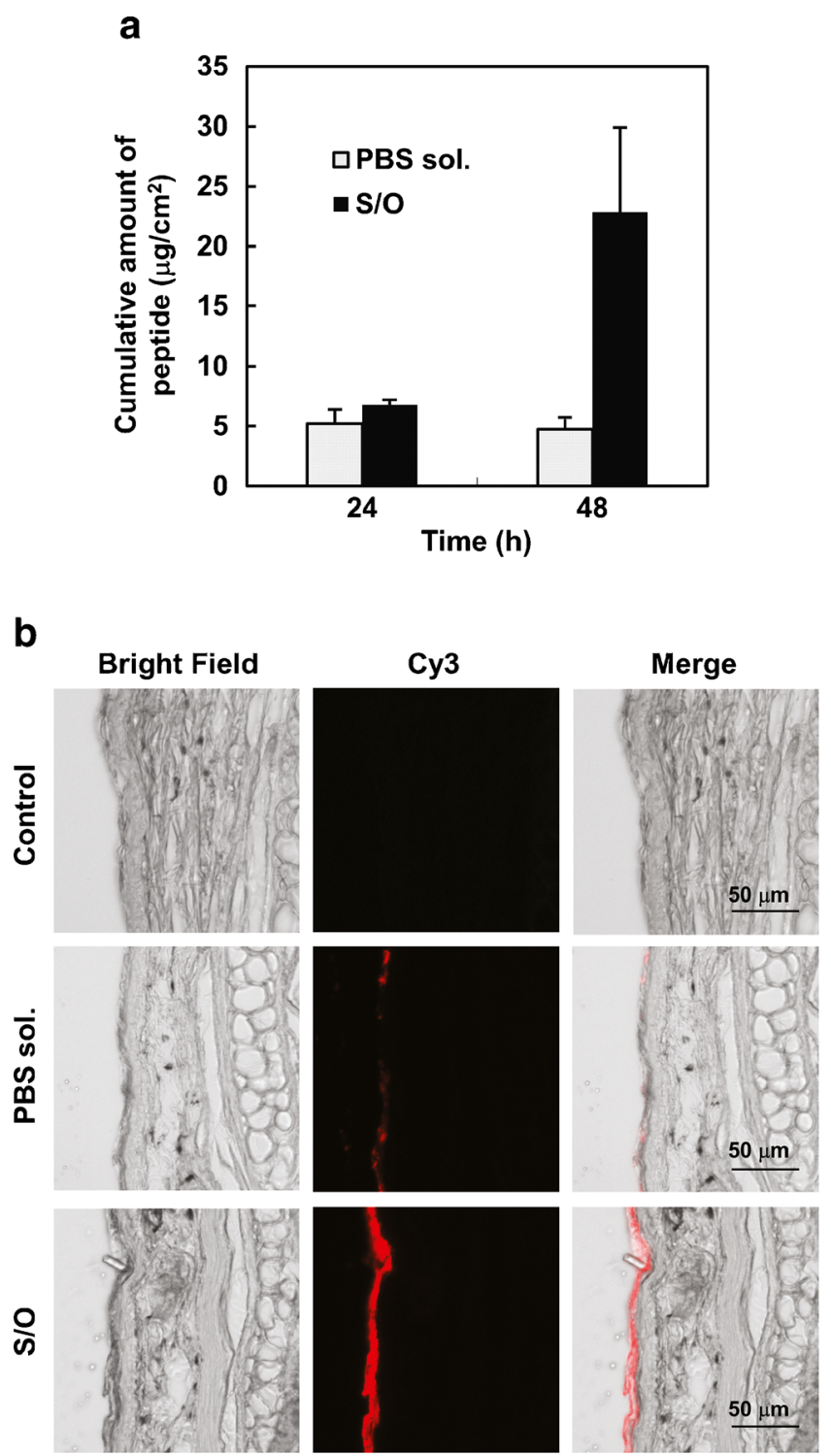

Fig. 3. In vitro skin permeation test of $\mathrm{Cy} 3-7 \mathrm{crpR}$ in the Yucatan micropig (YMP) back skin after application of the S/O nanodispersions (a) and in vivo skin permeation of Cy3-7crpR in mouse auricle (b). Data expressed as the mean $\pm \mathrm{SD}(n=3)$. Auricle sections were prepared from mouse auricles subjected to the $\mathrm{S} / \mathrm{O}$ nanodispersion for $24 \mathrm{~h}$ and analyzed by fluorescence microscopy with an objective lens of $\times 20$

administered S/O nanodispersions containing 7crpR were lower than that from control mice (Fig. 4b). A significant reduction of Cry j 1-specific IgE level was observed when a S/O nanodispersion containing $10 \mu \mathrm{g}$ of $7 \mathrm{crpR}$ was administered three times (Fig. 4c). Both total IgE levels and Cry j 1-specific IgE levels in sera from mice to which $50 \mu \mathrm{g}$ of $7 \mathrm{crpR}$ PBS solution were administered by subcutaneous injection were significantly lower than those from control mice.

\section{DISCUSSION}

We prepared a nano-sized carrier for the transcutaneous administration of a $\mathrm{T}$ cell epitope peptide for immunotherapy of $\mathrm{Cj}$ pollinosis mouse models. The previously reported peptide $7 \mathrm{crp}$ was a simple combination of $\mathrm{T}$ cell epitope 
a

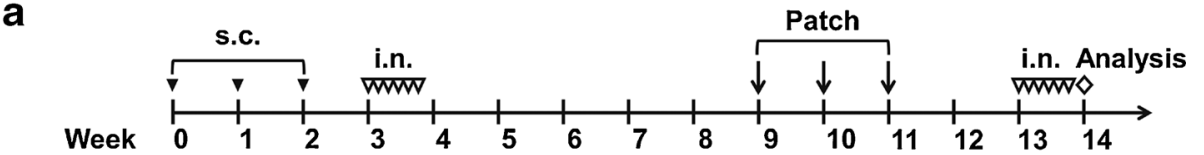

b

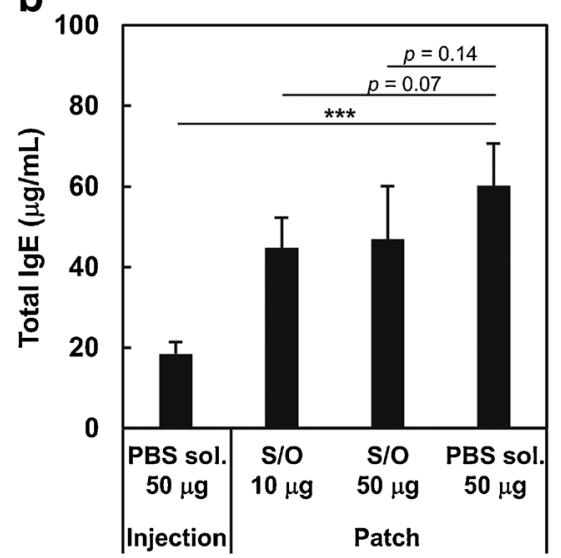

C

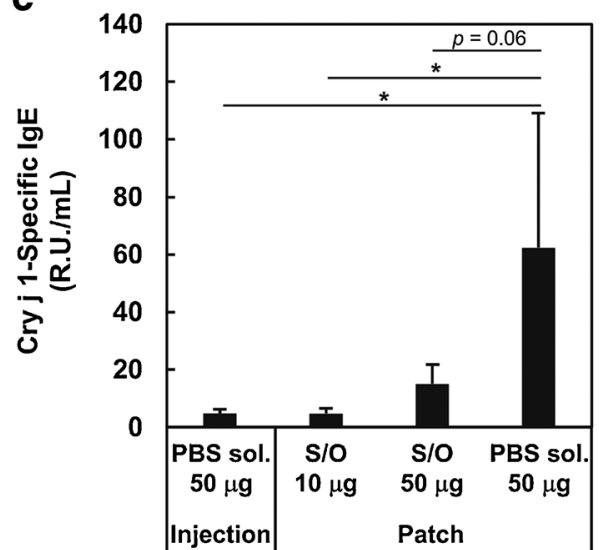

Fig. 4. Sensitization and peptide administration schedule (a) to B10.S mice and serum total IgE (b) and Cry j 1-specific IgE (c) levels of the mice after therapeutic treatment with $7 \mathrm{crpR}$. Mice were sensitized to $\mathrm{Cj}$ pollen extract by subcutaneous injection (s.c.). Pollinosis symptoms were generated by intranasal (i.n.) challenge with the $\mathrm{Cj}$ pollen extract. The peptide $7 \mathrm{crpR}$ was transcutaneously administered with patches on both auricles. Data show the mean and SD $(n=4-6)$. ${ }^{*} p<0.05$; $* * * p<0.0001$

determinants and, thus, was hydrophobic and intrinsically had a low solubility in water. Therefore, $7 \mathrm{crp}$ was not produced in large quantity in E. coli unless it was fused to a solubilityenhancing glutathione S-transferase (GST)-tag as reported previously (16). Since we assumed that a rather higher solubility in body fluid (more than $1 \mathrm{mg} / \mathrm{mL}$ ) was desirable for administration by injection or by S/O nanodispersion system, we introduced small linkers (triarginine) between the epitopes in $7 \mathrm{crp}$ and designed a new peptide $7 \mathrm{crpR}$ (Fig. 1). The 7crpR was composed of 126 amino acids (14.8 kDa), however, smaller than 7crp-GST conjugate ( $35 \mathrm{kDa})$. The T cell receptor is known to recognize linear epitopes, and peptide linkers actually had no effect on peptide activity in T cell proliferation assay in the previous report (11). After production of $7 \mathrm{crpR}$ in E. coli, the peptide size was confirmed by SDS-PAGE. The mobility of $7 \mathrm{crpR}$ was slightly slower than estimated because of positively charged arginine likers. The peptide $7 \mathrm{crpR}$ was soluble in Milli-Q water $(6 \mathrm{mg} / \mathrm{mL})$ and no precipitation was observed after storage for 2 month at $4{ }^{\circ} \mathrm{C}$, indicating that the water solubility of $7 \mathrm{crp}$ was successfully increased by the introduction of triarginine linkers.

Then, we prepared a $\mathrm{S} / \mathrm{O}$ nanodispersion using sucrose laurate (L-195) as a surfactant surrounding the peptide. A single-dispersed S/O nanodispersion with an average diameter of $230 \mathrm{~nm}$ was obtained according to the result of DLS analysis (Fig. 2a). The surfactant-protein complexes in SEM images had a spherical shape with a smooth surface. The sizes of particles in the SEM images were less than $500 \mathrm{~nm}$ (Fig. 2b), showing a good correspondence with the DLS result.

In vitro skin permeation efficiency of the peptide in $\mathrm{S} / \mathrm{O}$ nanodispersion was examined using Cy3-labeled $7 \mathrm{crpR}$. The $\mathrm{S} / \mathrm{O}$ nanodispersion system assisted the permeation of peptide 4.8-fold higher than did PBS solution in $48 \mathrm{~h}$; however, the skin permeation efficiency of $7 \mathrm{crpR}$ was slower compared to that of OVA. In the previous experiment delivering OVA, the $\mathrm{S} / \mathrm{O}$ nanodispersion system increased the protein permeation by10-fold in $24 \mathrm{~h}$ (25). This difference may be relevant to the hydrophobicity of the peptide/protein. The peptide $7 \mathrm{crpR}$ does not have specific conformation and composed of $38 \%$ hydrophobic amino acids. Consequently, $7 \mathrm{crpR}$ had a higher affinity for sucrose laurate which hydrophile-lipophile balance value is 1 . Our previous investigations demonstrated a mechanism of protein permeation through the $\mathrm{S} / \mathrm{O}$ nanodispersion system: surfactant molecules were removed in the outermost SC layer and hydrophilic molecules only permeate into the hydrophilic layers in skin (20). Thus, inefficient removal of surfactant depressed the permeation of $7 \mathrm{crpR}$ into epidermis. Further introduction of hydrophilic peptide linkers may improve the skin penetration efficiency of $7 \mathrm{crpR}$. Fluorescence microscopic images of mouse auricle sections more clearly revealed that the $\mathrm{S} / \mathrm{O}$ nanodispersion system facilitated permeation of Cy3-7crpR. Since the mouse auricle skin is thinner than the YMP back skin, the difference in peptide permeation was obvious. In addition, the SC layer in mouse ears subjected to $\mathrm{S} / \mathrm{O}$ nanodispersion became thicker than that subjected to peptide PBS solution after $48 \mathrm{~h}$ of patches. These results implied that the SC layer could act as a reservoir for $\mathrm{S} / \mathrm{O}$ nanodispersion to help the peptide being released after the removal of patches.

Serum total IgE and Cry j 1-specific IgE levels were decreased by subcutaneous injection of $7 \mathrm{crpR}$ PBS solution. Thus, we assumed that the combined seven $\mathrm{T}$ cell epitope peptides held a curative effect on the pollinosis symptoms in this model after introduction of triarginine linkers. Declines in total IgE and Cry j 1-specific IgE levels also occurred in mouse sera receiving $\mathrm{S} / \mathrm{O}$ nanodispersions containing $7 \mathrm{crpR}$ via the auricle skin. Transcutaneous administration of $7 \mathrm{crpR}$ using the $\mathrm{S} / \mathrm{O}$ nanodispersion system reduced serum total IgE level 
little compared to the subcutaneous administration by injection, probably because the technique induced a slow antibody response compared to the injection method. Serum Cry j 1specific IgE level decreased significantly by the administration of the S/O nanodispersion containing $10 \mu \mathrm{g}$ of $7 \mathrm{crpR}$. Previously, smaller amount of $7 \mathrm{crp}$ fused with chicken egg white lysozyme ( $0.3 \mu \mathrm{g}$ per day, 5 days a week, 4 weeks) applied orally as an edible vaccine reduced serum total $\operatorname{IgE}$ and Cry $\mathrm{j}$ 1-specific IgE levels similar to the experiments described here (16). Moreover, administration of a higher concentration of $7 \mathrm{crpR}$ in PBS (4 mg/mL, the amount of $7 \mathrm{crpR}: 200 \mu \mathrm{g}$ ) by subcutaneous injection did not reduce serum total IgE level in our preliminary study. Therefore, an optimal amount of 7crpR-containing S/O nanodispersion for therapeutic treatment of $\mathrm{Cj}$ pollinosis might be less than those examined here. In the present study, optimizations of amino-acid linker length, surfactant-peptide ratio, along with the peptide dose have not yet examined. Investigations on these factors, along with the effects of adjuvants and skin-permeation enhancing peptides would improve the efficacy of transcutaneous administration of the peptide vaccine for $\mathrm{Cj}$ pollinosis using the $\mathrm{S} / \mathrm{O}$ nanodispersion system.

\section{CONCLUSION}

We developed a novel transcutaneous peptide administration system for therapeutic treatment of pollinosis. A $\mathrm{S} / \mathrm{O}$ nanodispersion containing an integrated $\mathrm{T}$ cell epitope peptide $7 \mathrm{crpR}$ was prepared for transcutaneous administration to a mouse model of Japanese cedar pollen allergy. Size, morphology, and skin-permeation efficiency of the nanoparticle were characterized. A significant reduction of antigen-specific $\operatorname{IgE}$ in the serum was observed by the transcutaneous administration of the $\mathrm{S} / \mathrm{O}$ nanodispersion containing $7 \mathrm{crpR}$, indicating that the $\mathrm{S} / \mathrm{O}$ nanodispersion system could be used for the future treatment of Japanese cedar pollinosis.

\section{ACKNOWLEDGMENTS}

This work was financed by a Grant-in-Aid for Scientific Research (S) 24226019 from the Ministry of Education, Culture, Sports, Science and Technology of Japan (to M. G.). SEM analysis was performed at Analytical Center in Fukuoka Industry-academia Symphony. We would like to thank Professor Yoshiki Katayama for animal experiments.

Conflict of Interest The authors declare that they have no competing interests.

\section{REFERENCES}

1. Yamada T, Saito H, Fujieda S. Present state of Japanese cedar pollinosis: the national affliction. J Allergy Clin Immunol. 2014;133:632-9.

2. Okamoto Y, Horiguchi S, Yamamoto H, Yonekura S, Hanazawa T. Present situation of cedar pollinosis in Japan and its immune responses. Allergol Int. 2009;58:155-62.

3. Sakaguchi M, Hirahara K, Fujimura T, Toda M. Approaches to immunotherapies for Japanese cedar pollinosis. Auris Nasus Larynx. 2011;38:431-8.
4. Okubo K, Gotoh M. Sublingual immunotherapy for Japanese cedar pollinosis. Allergol Int. 2009;58:149-54.

5. Möller C, Dreborg S, Ferdousi HA, Halken S, Høst A, Jacobsen $\mathrm{L}$, et al. Pollen immunotherapy reduces the development of asthma in children with seasonal rhinoconjunctivitis (the PAT-study). J Allergy Clin Immunol. 2002;109:251-6.

6. Durham SR, Walker SM, Varga EM, Jacobson MR, O'Brien F, Noble W, et al. Long-term clinical efficacy of grass-pollen immunotherapy. N Engl J Med. 1999;341:468-75.

7. Moldaver D, Larché M. Immunotherapy with peptides. Allergy. 2011;66:784-91.

8. Hoyne GF, O'Hehir RE, Wraith DC, Thomas WR, Lamb JR. Inhibition of $\mathrm{T}$ cell and antibody responses to house dust mite allergen by inhalation of the dominant T cell epitope in naïve and sensitized mice. J Exp Med. 1993;178:1783-8.

9. Bauer L, Bohhle B, Jahn-Schmid B, Wiedermann U, Daser A, Renz $\mathrm{H}$, et al. Modulation of the allergic immune response in $\mathrm{BALB} / \mathrm{c}$ mice by subcutaneous injection of high doses of the dominant $\mathrm{T}$ cell epitope from the major allergen Bet v 1. Clin Exp Immunol. 1997;107:536-41.

10. Hashimoto M, Nigi H, Sakaguchi M, Inouye S, Imaoka K, Miyazawa $\mathrm{H}$, et al. Sensitivity to two major allergens (Cry j I and Cry j II) in patients with Japanese cedar (Cryptomeria japonica) pollinosis. Clin Exp Allergy. 1995;25:848-52.

11. Hirahara K, Tatsuta T, Takatori T, Ohtsuki M, Kirinaka H, Kawaguchi J, et al. Preclinical evaluation of an immunotherapeutic peptide comprising 7 T-cell determinants of Cry j 1 and Cry j 2, the major Japanese cedar pollen allergens. J Allergy Clin Immunol. 2001;108:94-100.

12. Yoshitomi T, Hirahara K, Kawaguchi J, Serizawa N, Taniguchi Y, Saito S, et al. Three T-cell determinants of Cry j 1 and Cry j 2, the major Japanese cedar antigens, retain their immunogenicity and tolerogenicity in a linked peptide. Immunology. 2002;107:517-22.

13. Miyaji K, Yurimoto T, Saito A, Yasueda H, Takase Y, Shimakura $\mathrm{H}$, et al. Analysis of conformational and sequential IgE epitopes on the major allergen Cry j 2 of Japanese cedar (Cryptomeria japonica) pollen in humans by using monoclonal antibodies for Cry j 2. J Clin Immunol. 2013;33:977-83.

14. Hirahara K, Saito S, Serizawa N, Sasaki R, Sakaguchi M, Inouye $\mathrm{S}$, et al. Oral administration of a dominant T-cell determinant peptide inhibits allergen-specific $\mathrm{T}_{\mathrm{H}} 1$ and $\mathrm{T}_{\mathrm{H}} 2$ cell responses in Cry j 2-primed mice. J Allergy Clin Immunol. 1998;102:961-7.

15. Takagi H, Hiroi T, Yang L, Tada Y, Yuki Y, Tkamura K, et al. A rice-based edible vaccine expressing multiple $\mathrm{T}$ cell epitopes induces oral tolerance for inhibition of Th2-mediated IgE responses. Proc Natl Acad Sci. 2005;102:17525-30.

16. Kawabe Y, Hayashida Y, Numata K, Harada S, Hayashida Y, Ito A, et al. Oral immunotherapy for pollen allergy using T-cell epitope-containing egg white derived from genetically manipulated chickens. PLoS ONE. 2012;7, e48512.

17. Takagi H, Saito S, Yang L, Nagasaka S, Nishizawa N, Takaiwa F. Oral immunotherapy against a pollen allergy using a seed-based peptide vaccine. Plant Biotechnol J. 2005;3:521-33.

18. Verma P, Thakur AS, Deshmukh K, Jha AK, Verma S. Routes of drug administration. Int J Pharm Study Res. 2010;1:54-9.

19. Ortiz M, Jornada DS, Pohlmann AR, Guterres SS. Development of novel chitosan microcapsules for pulmonary delivery of dapsone: characterization, aerosol performance, and in vivo toxicity evaluation. AAPS PharmSciTech. 2015. doi:10.1208/s12249-0150283-3.

20. Tahara Y, Namatsu K, Kamiya N, Hagimori M, Kamiya S, Arakawa M, et al. Transcutaneous immunization by a solid-inoil nanodispersion. Chem Commun. 2010;46:9200-2.

21. Kitaoka M, Imamura K, Hirakawa Y, Tahara Y, Kamiya N, Goto M. Sucrose laurate-enhanced transcutaneous immunization with a solid-in-oil nanodispersion. Med Chem Commun. 2014;5:20-4.

22. Tahara Y, Honda S, Kamiya N, Goto M. Transdermal delivery of insulin using a solid-in-oil nanodispersion enhanced by arginine-rich peptides. Med Chem Commun. 2012;3:1496-9.

23. Tsunematsu M, Yamaji T, Kozutsumi D, Murakami R, Nagai H, Kino K. A new murine model of allergic rhinitis by repeated intranasal Cry j 1 challenge. Biomed Res. 2008;29:119-23. 
24. Tsunematsu M, Yamaji T, Kozutsumi D, Murakami R, 25. Kitaoka M, Naritomi A, Hirakawa Y, Kamiya N, Goto M. Kimura S, Kino K. Establishment of an allergic rhinitis model in mice for the evaluation of nasal symptoms. Life Sci. 2007;80:1388-94.

Transdermal immunization using solid-in-oil nanodispersion with $\mathrm{CpG}$ oligodeoxynucleotide adjuvants. Pharm Res. 2014;32:1486-92. 